\title{
LXII. Experimental researches on the temperature of the Sun
}

\section{F. Rosetti}

To cite this article: F. Rosetti (1879) LXII. Experimental researches on the temperature of the Sun, Philosophical Magazine Series 5, 8:52, 537-550, DOI: $10.1080 / 14786447908639725$

To link to this article: http://dx.doi.org/10.1080/14786447908639725

Published online: 13 May 2009.

Submit your article to this journal ๘

Џ Article views: 3

Q View related articles ¿

4 Citing articles: 1 View citing articles 준 


\section{$\left[\begin{array}{lll}537 & 0\end{array}\right.$}

LXII. Experimental Researches on the Temperature of the Sun. By F. Rosetri, Professor of Plysics in the University of Padua.

[Concluded from p. 449.]

\section{Thermal Radiation of the Sun.}

TWHE observations on the thermal effect of the radiation of 1 the sun were made with pile No. 1 (Duboscq), placed upon a platform near to the galvanometer. The pile could easily be directed so that the rays of the sun fell perpendicularly on its face. Four readings of the galvanometer were made for each observation :- the first with an open circuit, in order to determine the point of rest on the scale; the second with a closed circuit and the case of the pile closed; the third with the case open and the rays admitted; the fourth with the window of the case open, but intercepting the rays of the sun with a small circular screen with double walls placed at about a metre from the pile, so that its shadow was thrown on the window. In this fourth observation the face of the pile receives the radiation from the part of the sky surrounding the sun, which exercises an influence also in the third observation. Thus, by taking the difference between the third and fourth readings, the thermal effect of the solar radiation is obtained in scaledivisions. I should remark in passing, that the fourth reading was nearly always negative.

The electric current produced by the solar radiation was so great, that I had to introduce into the circuit sixteen Siemens's resistance units.

In order to determine the depth of the atmospheric layer traversed by the solar rays before arriving at the pile, in the first experiments the time of the third observation was noted : thus by means of the ephemerides the zenithal distance could be calculated. In the later experiments the determinations were made directly with a theodolite. When one of the observers had made the first two readings, the other (who was on the platform) opened the window of the case containing the pile, observing at the same time by means of a theodolite the height of the sun above the horizon; in the meantime the first observer had made the third reading with the galvanometer. The hygrometric state of the air was also ascertained each time; and in order to obtain an immediate indication, a hair hydrometer was used. This hygrometer had been graduated by comparing it with a condensation lyggrometer. The following Table shows relative humidity corresponding to the

Phil. Mag. S. 5. No. 52. Suppl. Vol. 8. 
degrees marked on the instrument. When the air contained an excessive amount of moisture the index went beyond $100^{\circ}$.

\section{TABLE IV.}

$$
\text { Hygrometer. Relative humidity. }
$$

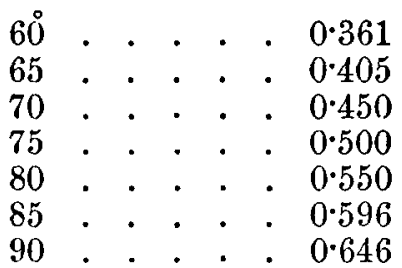

Barometric observations were also made; but we shall see that these indications, as well as those of the hygrometer, cannot be used except in cases of simultaneous observations made at different altitudes. Before giving the tables of observations, it may be useful to show how the value of $\epsilon$, representing the thickness of the atmospheric stratum traversed by the rays of the sun, has been calculated. If at the time of the observation the sun is not more than $60^{\circ}$ from the zenith, the formula $\epsilon=\sec Z$ gives us the value nearly enough. When the sun is lower, it is necessary to calculate $\epsilon$ by a formula which gives exact results. At the Mont Souris observatory Pouillet's formula is employed; but when the distance from the zenith is great, this gives too small a value for $\epsilon$. The values which I have entered in the following Tables are calculated from the formula of Bouguer and Laplace, which gives exact and concordant results.

In order to obtain the values quickly, I constructed a curve, the abscissæ of which represent the zenithal distances, and the ordinates the corresponding values of $\epsilon$. In order to trace the curve I used the values contained in the following Table, which have been calculated by Forbes with the formula of Laplace.

TABLE V.

\begin{tabular}{|c|c|c|c|}
\hline $\begin{array}{c}\text { Distance from } \\
\text { zenith. } \\
Z .\end{array}$ & c. & $\begin{array}{c}\text { Distance from } \\
\text { zenith. } \\
Z .\end{array}$ & $\varepsilon$. \\
\hline 8 & 1.000 & 75 & \\
10 & 1.016 & 80 & 3.809 \\
20 & 1.065 & 85 & 5.57 \\
30 & 1.156 & 86 & $12 \cdot 2$ \\
40 & 1.306 & 87 & 14.9 \\
50 & 1.555 & 88 & 18.9 \\
60 & 1.995 & 89 & 25.1 \\
70 & 2.902 & 90 & 35.5 \\
\hline
\end{tabular}


on the Temperature of the Sun.

From amongst the number of observations made from the month of August till December, I shall only give those of 28th and 29 th September, which were very favourable, because the sky kept clear and the air was tranquil and very transparent.

\section{TABLE VI.}

Observations on the Thermal Radiation of the Sun, 28th of September, 1877.

\begin{tabular}{|c|c|c|c|}
\hline Time. & $\begin{array}{l}\text { Distance from } \\
\text { zenith. } \\
\text { Z, }\end{array}$ & $\mid \begin{array}{c}\text { Deflections of } \\
\text { galvanometer. } \\
y .\end{array}$ & Hygrometer. \\
\hline $\begin{array}{rr}\mathrm{h} & \mathrm{m} \\
8 & 30 \\
9 & 0 \\
10 & 0 \\
11 & 0 \\
11 & 35 \\
12 & 0 \\
1 & 0 \\
2 & 15 \\
3 & 0 \\
4 & 0 \\
4 & 35\end{array}$ & $\begin{array}{ll}64 & 54 \\
60 & 42 \\
53 & 27 \\
47 & 36 \\
47 & 34 \\
50 & 12 \\
57 & 23 \\
63 & 23 \\
72 & 43 \\
78 & 36\end{array}$ & $\begin{array}{c}\text { div. } \\
188.0 \\
191.0 \\
202.0 \\
209.2 \\
210.0 \\
207.0 \\
191.0 \\
184.5 \\
164.0 \\
131.0\end{array}$ & $\begin{array}{l}89 \\
89 \\
86 \\
82 \\
80 \\
74 \\
71 \\
68 \\
69 \\
76\end{array}$ \\
\hline
\end{tabular}

\section{TABLE VII.}

29th September. $\mathrm{H}=768, t=16^{\mathrm{C}} \cdot 5 \mathrm{C}$.

\begin{tabular}{|c|c|c|c|}
\hline Time. & $\begin{array}{c}\text { Distance from } \\
\text { zenith. } \\
\mathbf{Z} .\end{array}$ & $\mid \begin{array}{c}\text { Reading on } \\
\text { galvanometer. } \\
y .\end{array}$ & Hygrometer. \\
\hline $\begin{array}{rr}\mathrm{h} & \mathrm{m} \\
8 & \mathbf{4 5} \\
9 & 5 \\
9 & \mathbf{3 5} \\
10 & 5 \\
10 & \mathbf{3 5} \\
11 & 5 \\
11 & \mathbf{3 5} \\
12 & 2 \\
1 & 40 \\
2 & 5 \\
3 & 5 \\
3 & 45 \\
4 & 30 \\
4 & 50\end{array}$ & $\begin{array}{rr}63 & 48 \\
60 & 22 \\
56 & 36 \\
53 & 21 \\
50 & 48 \\
49 & 0 \\
48 & 0 \\
48 & 0 \\
53 & 48 \\
56 & 36 \\
64 & 30 \\
70 & 36 \\
78 & 5 \\
81 & 24\end{array}$ & $\begin{array}{c}\text { div. } \\
180 \cdot 5 \\
186 \cdot 5 \\
192 \cdot 0 \\
197 \cdot 0 \\
200 \cdot 0 \\
201 \cdot 0 \\
204 \cdot 5 \\
205 \cdot 0 \\
190 \cdot 0 \\
189 \cdot 0 \\
174 \cdot 0 \\
155 \cdot 0 \\
130 \cdot 0 \\
109 \cdot 0\end{array}$ & $\begin{array}{l}92 \cdot 5 \\
92 \cdot 5 \\
92 \cdot 0 \\
91 \cdot 0 \\
90 \cdot 0 \\
88 \cdot 5 \\
86 \cdot 0 \\
82 \cdot 0 \\
74 \cdot 0 \\
74 \cdot 0 \\
71 \cdot 0 \\
74 \cdot 0 \\
74 \cdot 0\end{array}$ \\
\hline
\end{tabular}

Although the two days, 28 th and 29 th of September, were 202 
very favourable for the experiments, we see, nevertheless, that at an equal zenithal distance (i. e. with an equal thickness of the atmospheric stratum for the rays to traverse) the observations of the morning are not altogether concordant with those of the afternoon. Amongst the observations of 29th of September we find, for example, that the observations of $9 \mathrm{~b} .35 \mathrm{~m}$. gave a deflection of 192 divisions, whilst that of $2 \mathrm{~h} .5 \mathrm{~m}$. only gave 189 divisions; and in both cases the distance from the zenith was equal to $56^{\circ} 36^{\prime}$. In the same way, in the observations of 28th of September we obtain 191 divisions when the thickness of the stratum of air traversed, at 9 in the morning, corresponded to $60^{\circ} 42^{\prime}$ distance from the zenith; whilst at $2 \mathrm{~h}$. $15 \mathrm{~m}$. we had the same deflection of 191 divisions, notwithstanding the decreased thickness of the atmospheric stratum. In general I found that the observations of the morning gave a somewhat smaller deflection than those of the afternoon, although the hygrometer almost always indicated a less degree of moisture in the afternoon than in the morning. But just this coincidence gives the key to the explanation of the phenomenon. In the morning the lower strata of the atmosphere, those which can influence the hygrometer, contain a large quantity of vapour, while the upper strata contain a much smaller quantity of it; but as the sun rises, the vapour also rises, and expands into the higher regions of the atmosphere. In the morning the upper strata of the atmosphere are less saturated with vapour, and consequently absorb less heat; in the afternoon, on the contrary, the absorption becomes greater on account of the preponderating action of the vapour expanded into the higher strata, whilst at the same time the lower strata are drier.

On constructing curves with the data contained in the two preceding Tables, taking for abscissa the values of $\epsilon$ corresponding to the distances from the zenith entered in the second column, and for ordinates the values of the deflections of the galvanometer, we obtain for each day two dissimilar curves. 1 preferred to construct only the curve for the afternoon, as, the points lying usually in a straight line, it could be drawn easily and with great precision. In Table VIII. the values of the coordinates obtained from the curves are given. 
on the Temperature of the Sun.

TABLE VIII.

\begin{tabular}{|c|c|c|c|c|c|c|c|}
\hline \multicolumn{2}{|c|}{$\begin{array}{l}\text { Date of } \\
\text { observ. }\end{array}$} & e. & $\begin{array}{c}\text { Scale- } \\
\text { divisions. } \\
y .\end{array}$ & \multicolumn{2}{|l|}{ Date. } & e. & $\begin{array}{c}\text { Scale- } \\
\text { divisions. } \\
y .\end{array}$ \\
\hline Sept. 28. & ....... & 1.30 & 217 & Oct. 21. & & 4.80 & 1372 \\
\hline$"$ & ....... & 3.40 & 213 & , & 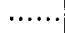 & $5 \cdot 40$ & $128 \cdot 3$ \\
\hline$"$ & ..... & 1.50 & 210 & Not. 1. & & 1.80 & $197 \cdot 3$ \\
\hline$"$ & ..... & $1 \cdot 60$ & $205 \cdot 3$ & ", & $\cdots$ & $2 \cdot 10$ & 187.5 \\
\hline " & $\ldots$. & $1 \cdot 80$ & 198.0 & " & .... & $2 \cdot 50$ & $170 \cdot 2$ \\
\hline$"$ & $\cdots$ & $2 \cdot 00$ & $191 \cdot 2$ & $"$ & .... & 300 & 1560 \\
\hline$"$ & ..... & $2 \cdot 20$ & 185.0 & ", & $\ldots$ & 350 & $145 \cdot 0$ \\
\hline$"$ & ..... & 260 & 1723 & $"$ & $\cdots$ & $4 \cdot 00$ & 1367 \\
\hline$"$ & ..... & $3 \cdot 0$ & 1620 & $"$ & $\ldots$ & 450 & $130 \cdot 0$ \\
\hline$"$ & ... & $3 \cdot 20$ & $1 \% 8 \cdot 0$ & , & $\ldots$ & $5 \cdot 00$ & $123 \cdot 6$ \\
\hline " & ... & $3 \cdot 60$ & 152.0 & $"$ & $\ldots$ & 260 & $166 \cdot 1$ \\
\hline$"$ & ....... & $4 \cdot 1) 0$ & 145 & ", & $\ldots$ & $3 \cdot 00$ & $160 \cdot 2$ \\
\hline & & 4.97 & $131 \cdot 0$ & $"$ & $\ldots$ & 320 & 153.0 \\
\hline Sept. 29. & ...... & $\mathrm{J} \cdot \mathbf{4 0}$ & $206 \cdot 8$ & ", & $\ldots$ & 3.50 & 145.5 \\
\hline ", & $\ldots$ & $1 \cdot \mathbf{3} 0$ & $202 \cdot 9$ & $"$ & ........ & 4.00 & $138 \cdot 0$ \\
\hline$"$ & $\ldots$ & $2 \cdot 00$ & $184 \cdot 8$ & $"$ & $\ldots$. & 4.50 & $132 \cdot 7$ \\
\hline & ....... & $2 \cdot 50$ & 169.0 & $"$ & ..... & 484 & $130 \cdot 0$ \\
\hline Oet. 2. & $\ldots .$. & $1 \cdot 60$ & 198.7 & $"$ & $\ldots$ & $5 \cdot 00$ & 128.1 \\
\hline$"$ & ....... & 200 & 178.5 & " & $\ldots$ & 5 & $123 \cdot 0$ \\
\hline$"$ & ....... & 250 & 164.9 & $"$ & $\ldots$ & 6 & 109.0 \\
\hline " & $\ldots \ldots$ & 3.00 & 15 & & $\ldots$ & 1 & $197 \cdot 4$ \\
\hline ", & $\ldots \ldots$ & 330 & 1580 & Oct 19. & $\ldots$ & $2 \cdot 00$ & 190.5 \\
\hline$"$ & $\ldots$ & $3 \cdot 60$ & $147 \cdot 3$ & $"$ & & 250 & 84.9 \\
\hline Oct. 3. & $\ldots \ldots$ & 160 & 181.5 & $"$ & $\ldots$ & $3 \cdot 00$ & 161.8 \\
\hline ", & $\ldots \ldots$ & 200 & 164.8 & " & $\ldots$ & 3.50 & $149 \cdot 3$ \\
\hline$"$ & ....... & $2 \cdot 50$ & 149.2 & $"$ & $\ldots$ & 4 & $137 \cdot 5$ \\
\hline$"$ & $\ldots \ldots$ & $3 \cdot 00$ & 135.8 & $"$ & ... & 4.5 & 125.5 \\
\hline$"$ & $\ldots \ldots$ & $3 \cdot 50$ & $125 \cdot 0$ & " & $\ldots$ & 5 . & $114 \cdot 0$ \\
\hline & $\ldots \ldots$ & $4 \cdot 00$ & $117 \cdot 0$ & $"$ & $\ldots$ & $5 \cdot 50$ & $104 \cdot 2$ \\
\hline Oct. 10. & ....... & $1 \cdot 60$ & 2060 & ", & & $6 \cdot 00$ & $98 \cdot 8$ \\
\hline ", & $\ldots .$. & 180 & ]y & " & & 5 & 118.0 \\
\hline . & $\ldots \ldots$ & $2 \cdot 00$ & $191 \cdot 5$ & & & $6 \cdot 00$ & $112 \cdot 0$ \\
\hline 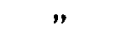 & $\ldots \ldots$ & $2 \cdot 30$ & 182.5 & Dec. 17. & $\ldots$. & $2 \cdot 7$ & 180.11 \\
\hline & & $2 \cdot 80$ & $170 \cdot 9$ & $"$ & ..... & $\mathbf{3} \cdot \mathbf{3}$ & 165.5 \\
\hline Oct. 19. & $\ldots \ldots$ & 6.50 & $90 \cdot 0$ & 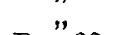 & $\ldots$ & 3 & 154.0 \\
\hline & & 7.00 & $83 \cdot 1)$ & Dec. 22. & ..... & $2 \cdot 7$ & 1623 \\
\hline Oct. 21. & $\ldots \ldots$ & 1.80 & $200 \cdot 9$ & $"$ & $\ldots$ & $3 \cdot 3$ & $148 \cdot 1\}^{*}$ \\
\hline , & ....... & $2 \cdot 40$ & $179 \cdot 8$ & $"$ & & 399 & $137 \cdot 6$ \\
\hline$"$ & ....... & $3 \cdot 00$ & ] $66^{\circ} 6^{2}$ & $"$ & $\ldots .$. & 4 & 1288 \\
\hline$"$ & .. & $3 \cdot 60$ & 156 & " & & 5 & 120.3 \\
\hline 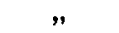 & $\ldots$. & $4 \cdot 20$ & $146 \cdot 1$ & $"$ & ........ & $5 \cdot 7$ & 112.5 \\
\hline
\end{tabular}

IX. Determination of the Thermal Absorption of the Atmosphere.

The deflections $y$ which have been observed on the galvanometer are produced by the pencil of solar rays which falls on the face of the pile, after having traversed a stratum of air more or less thick according to the altitude of the sun. In this passage the thermal effect of the rays is greatly lessened through absorption by the air, and especially by the vapour

$$
\text { - Hygrometer }=100 \text {. }
$$


contained therein. Before comparing the thermal effect of the rays of the sun with that of hot bodies placed at a short distance from the pile, it is necessary to find out what is the diminution produced by the atmospheric absorption in order to be able to calculate the thermal effect of the solar rays which fall on the face of the pile. To do this we first require to find out the law of absorption of the rays of the sun during their passage through the terrestrial atmosphere. It has been admitted by many physicists that the law is expressed by the formula

$$
q=a b^{\varepsilon}
$$

$q$ being the quantity of heat received in a unit of time by the unit of surface perpendicular to the direction of the rays in a place on the earth's surface,

$a$ and $b$ being two constants, and

$\epsilon$ a number which represents the thickness of the atmospheric stratum traversed by the rays, taking for unity the height of the atmosphere.

$a$ represents the quantity of heat which in unit time would be received on the unit surface perpendicular to the direction of the rays at the limits of the atmosphere; and this is the quantity which it is desired to determine.

$b$ is the proportion of the diminution of this quantity when the rays have traversed in the perpendicular direction the earth's atmosphere; and this is called the coefficient of absorption.

Violle attempted to determine the hygrometric state of the air; and he made simultaneous observations at different heights on Mont Blane. He found that the phenomenon was pretty well represented by the formula

in which $a, p, k$ are constants ;

$$
y=a p \frac{H+(Z-z) k f}{760} \epsilon ;
$$

$Z$, height of the atmospheric stratum beyond which the vapour appears to cease;

$z$, altitude of the place of observation ;

$f$, mean temperature of the vapour contained in the strata of air between $\mathrm{Z}$ and $z$;

$\epsilon$, thickness of the stratum of air traversed.

This is certainly the best method of expressing and estimating the law of atmospheric absorption; but it requires simultaneous observations at different altitudes, and is not applicable in the case of observations made at one and the same station. I have consequently been obliged to have recourse to other methods. I tried at first to apply the formula $q=a b^{\varepsilon}$ to the curves obtained in some dars of observations; but I soon 
found out that this single formula is not sufficient to represent the phenomenon for one entire day. I then tried to employ other empirical formulæ, and in particular the two more complex exponential formulæ

$$
\begin{aligned}
& q=a b \stackrel{e}{\gamma+\varepsilon}, \\
& q=\alpha+m \beta^{e}+n \gamma^{e},
\end{aligned}
$$

$a, b, m, n, \alpha, \beta, \gamma$ being empirical constants ; but not one of the formulæ employed is able to represent with sufficient precision the whole phenomenon.

In using the following three couples of values with the formula $q=a b^{\frac{\epsilon}{\gamma+\varepsilon}}$,

we obtain

$$
\begin{array}{ll}
\epsilon=1 \cdot 5, & q=203 \cdot 8, \\
\epsilon=2 \cdot 25, & q=174 \cdot 0, \\
\epsilon=3 \cdot 00, & q=152 \cdot 0,
\end{array}
$$

$$
\begin{aligned}
\gamma & =7 \cdot 06180, \\
\log b & =8 \cdot 966537-10, \\
a & =309 \cdot 27 .
\end{aligned}
$$

\begin{tabular}{|c|c|c|c|}
\hline E. & $q$ observed. & $q$ calculated. & Difference. \\
\hline 1.5 & 203.8 & & \\
1.75 & 192.6 & 192.76 & 0.16 \\
2.00 & 182.8 & 182.88 & 0.08 \\
$2 \cdot 25$ & 174.0 & & \\
2.50 & 166.0 & 165.98 & -0.02 \\
2.75 & 158.9 & 158.71 & -0.17 \\
2.00 & 152.1 & & \\
$4 \mathrm{i}$ & 132.7 & 134.42 & +1.72 \\
\hline
\end{tabular}

In this case the formula answers pretty well.

By applying the same formula to the curve of 28 th September for the interval $\epsilon=1 \cdot 4$ and $\epsilon=2 \cdot 6$, we obtain

$$
a=292 \cdot 25 \text {. }
$$

In the curve of 1 st November, interval $\epsilon=2 \cdot 0$ and $\epsilon=3 \cdot 2$, we have

For the 10th October,

$$
a=333 \cdot 24 \text {; }
$$

$$
a=339 \cdot 95 \text {. }
$$

The other curves would give results as mnch smaller as the interval taken for the calculation of the constants was greater.

21st October, interval $\epsilon=1.8$ and $\epsilon=10$,

$$
a=260 \cdot 9 \text {. }
$$

21st October, interval $\epsilon=1.8$ and $\epsilon=6$,

$$
a=272 \cdot 2 \text {. }
$$

But between the calculated values and the observed values the differences are too great, as the following Table shows:- 


\begin{tabular}{|c|c|c|c|}
\hline E. & $q$ observed. & $q$ calculated. & Difference. \\
\hline 1.8 & $200 \cdot 9$ & & \\
\hline $2 \cdot 4$ & 1798 & 183.97 & $+4 \cdot 17$ \\
\hline 30 & 1666 & $169 \cdot 41$ & +281 \\
\hline $3 \cdot 6$ & $156 \cdot 1$ & $156 \cdot 79$ & +0.61 \\
\hline $3 \cdot 9$ & $151 \cdot 1$ & & \\
\hline $4 \cdot 2$ & $146 \cdot 1$ & 1457 & -032 \\
\hline 4.8 & $137 \cdot 2$ & $136 \cdot 1$ & -1.1 \\
\hline $\begin{array}{l}5 \cdot 4 \\
6.0\end{array}$ & $\begin{array}{l}128 \cdot 2 \\
120 \cdot 0\end{array}$ & 127.58 & $-0 \cdot 62$ \\
\hline
\end{tabular}

The great differences which the calculated values exhibit in proximity to $\epsilon=1.8$ show that the calculated value of $a$ which corresponds to $\epsilon=0$ is much less than the true value. Consequently I have been obliged to abandon all hope of making use of a formula which is only empirical, and content myself with dividing the curve into a certain number of parts, and applying to each portion an equation of the form of $q=a b$, calculating each time the value of the constants $a$ and $b$. Naturally we thus obtain for each day of observation a series of different values for $a$ and another for $b$. It may be useful to give a Table of the results obtained by applying this method to the observations of several days.

\begin{tabular}{|c|c|c|c|c|c|}
\hline \multirow{2}{*}{ Date. } & \multirow{2}{*}{\multicolumn{2}{|c|}{$\begin{array}{c}\text { Intervalbetween } \\
\epsilon .\end{array}$}} & \multicolumn{2}{|c|}{$\begin{array}{l}\text { Values obtained by } \\
\text { formula. }\end{array}$} & \multirow{2}{*}{$\begin{array}{l}\text { Mean value } \\
\text { of } \epsilon \text {. }\end{array}$} \\
\hline & & & $a$. & $b$. & \\
\hline \multirow{4}{*}{ Sept. $28 \ldots \ldots \ldots$} & {$\left[\begin{array}{ll}1.4 \\
0\end{array}\right.$} & and $2 \cdot 0$ & 27368 & 0.83533 & $1 \cdot 7$ \\
\hline & $\begin{array}{l}2 \cdot 0 \\
2.6\end{array}$ & $\Rightarrow \quad \begin{array}{l}2 \cdot 6 \\
3.9\end{array}$ & $270 \cdot 49$ & 0.84080 & $2 \cdot 3$ \\
\hline & $\mid \begin{array}{l}2 \cdot 6 \\
3 \cdot 2\end{array}$ & $\Rightarrow \begin{array}{l}3 \cdot 2 \\
5 \cdot 0\end{array}$ & $\begin{array}{l}250 \cdot 79 \\
227 \cdot 71\end{array}$ & $\begin{array}{l}0.86557 \\
089954\end{array}$ & $\begin{array}{l}2 \cdot 9 \\
4 \cdot 1\end{array}$ \\
\hline & $(1.4$ & $" \quad 2 \cdot 0$ & $\begin{array}{l}227 \cdot 71 \\
272 \cdot 3\end{array}$ & $\begin{array}{l}089954 \\
082173\end{array}$ & $\begin{array}{l}4.1 \\
1.7\end{array}$ \\
\hline \multirow{5}{*}{ Sept. $29 \ldots \ldots \ldots$} & & $" 2 \cdot 6$ & 26375 & 0.8371 & $2 \cdot 3$ \\
\hline & & $" 3 \cdot 2$ & $237 \cdot 17$ & 0.8721 & $2 \cdot 9$ \\
\hline & & $\Rightarrow \quad 4.4$ & $210 \cdot 24$ & 0.9054 & $3 \cdot 8$ \\
\hline & 4.4 & $" \begin{array}{l}7 \cdot 0 \\
2 \cdot 1\end{array}$ & $196 \cdot 33$ & 0.909 & $\begin{array}{l}5 \cdot 7 \\
1 \cdot 8\end{array}$ \\
\hline & & $\begin{array}{ll} & 2 \cdot 1 \\
\Rightarrow & 2 \cdot 7\end{array}$ & $\begin{array}{l}271 \cdot 96 \\
240 \cdot 92\end{array}$ & $\begin{array}{l}0.77931 \\
0.8256\end{array}$ & $\begin{array}{l}1 \cdot 8 \\
2 \cdot 4\end{array}$ \\
\hline \multirow{4}{*}{ Oct. 3} & $2 \cdot 7$ & $" 3 \cdot 3$ & $234 \cdot 20$ & 0.8342 & $3 \cdot 0$ \\
\hline & $3 \cdot 3$, &,$\quad 39$ & 206.55 & 0.8667 & $3 \cdot 6$ \\
\hline & $1 \cdot 8$ & $" 2 \cdot 4$ & $280 \cdot 25$ & 0.8312 & $2 \cdot 1$ \\
\hline & & $\Rightarrow \quad 3 \cdot 0$ & $243 \cdot 9$ & 0.8807 & $2 \cdot 7$ \\
\hline \multirow{4}{*}{ Oct. 21} & &,$\quad 3 \cdot 6$ & $230 \cdot 7$ & 0.8972 & 33 \\
\hline & & $\Rightarrow \quad 4 \cdot 2$ & $232 \cdot 2$ & 0.8955 & $3 \cdot 9$ \\
\hline & 4.2 & $" 4.8$ & $226 \cdot 8$ & $0 \cdot 000$ & 45 \\
\hline & $\begin{array}{l}4.8 \\
1.7\end{array}$ & $" 5 \cdot 4$ & $\begin{array}{l}23+6 \\
051 \cdot 00\end{array}$ & 0.894 & $\begin{array}{l}5 \cdot 1 \\
2 \cdot 0\end{array}$ \\
\hline \multirow{3}{*}{ Oct. $14 \ldots \ldots . .}$. & $2 \cdot 3$ & $\begin{array}{ll}2 \cdot 3 \\
, & 2 \cdot 9\end{array}$ & $233 \cdot 08$ & 0.8484 & $2 \cdot 6$ \\
\hline & 29 & $" \quad \mathbf{3 5}$ & $2 \mathrm{~J} 7 \cdot 49$ & 0.8689 & $3 \cdot 2$ \\
\hline & 3.5 & $" 7 \cdot 74$ & $2 ध 2 \cdot 25$ & 0.8635 & $5 \cdot 6$ \\
\hline \multirow{3}{*}{ Dec. $17 \ldots \ldots \ldots$} & $2 \cdot 7$ & $" \ddot{3} \cdot 3$ & 2627 & 0.869 & 30 \\
\hline & 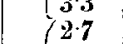 & $" \begin{array}{l}3 \cdot 9 \\
3 \cdot 3\end{array}$ & $245 \cdot 9$ & 0.867 & $\begin{array}{l}3 \cdot 6 \\
3 \cdot 0\end{array}$ \\
\hline & $3 \cdot 3$ & $\begin{array}{lll} & 0.0 \\
" & 3 \cdot 9\end{array}$ & 220.9 & $\begin{array}{l}0.8375 \\
0.8856\end{array}$ & 3.6 \\
\hline \multirow[t]{3}{*}{ Dec. $22 \ldots \ldots \ldots$} & 39 & $" 4.5$ & 2127 & 0.8943 & $4 \cdot 2$ \\
\hline & $4 \cdot 5$ & $" 5 \cdot 1$ & 213.2 & 08938 & 4.8 \\
\hline & $(5-1)$ & $" 5 \cdot 7$ & 2127 & 0.8943 & $5 \cdot 4$ \\
\hline
\end{tabular}


Now let us notice the values which were obtained for $a$ and $b$. The values of $b$ in each day's observations were found to increase with the value of $\epsilon$; but on different days, for one and the same value of $\epsilon$ we have different values of $b$. These facts have been noticed by former observers.

As I have already said, $b$ represents the ratio between the quantity of rays which arrive at the face of the pile at the place of observation, after having traversed perpendicularly the depth $\epsilon=1$ of the atmosphere, and the rays which it would receive if the atmosphere did not exist, $i$. e. if $\epsilon$ were equal to 0 . It is obvious that if the hygrometric state of the air were different on the different days, the values of $b$ obtained by means of the formula corresponding to one and the same value of $\epsilon$ would also be different.

It is in accordance with the laws of absorption that $b$ should increase as $\varepsilon$ increases. In short, the absorption of rays which pass through a transparent body is greater in the first strata than in the subsequent ones. The observations of 20 th September, 24th October, 21st October, and 22nd December show that, beyond a certain thickness $\epsilon$, the coefficient of absorption becomes constant.

Let us now consider the values of $a$. Each of these values represents, in the units chosen for the curve, the true quantity of heat which falls on the unit of surface at the limits of the atmosphere. We see, nevertheless, that as $\epsilon$ diminishes the value of $a$ increases; and it is evident that, if we had been able to make experiments with less thicknesses of $\epsilon$, we should have had greater values for $a$. If we express the values of $a$ graphically, taking for abscissæ the arithmetic means of the values of $\epsilon$ (which are found in the last column of the preceding Table) which have been employed in the calculation of each of the values of $a$, and for ordinates the corresponding values of $a$, we find that the different points thus determined arrange themselves with very few exceptions in a straight line. The more favourable the condition of the atmosphere on the day of observation, the more marked is this regularity.

Consequently, since a more exact method was required, I decided to take as the true value of $a$ that portion of the axis of the ordinates which lies between the origin and the point of contact of the above-mentioned straight line with the same axis. In order to obtain greater accuracy, I determined by the method of least squares the equation of the line $a=m+n \epsilon$, which approaches nearest to the points representing the values of $a$ corresponding to the different mean values of $\varepsilon$; and I took for the value of tho quantity sought the number $m$. This calculation was made for several curves obtained under very different conditions, and gave for $m$ such results as, if wo take into consideration the canses which necessarily influence 
observations of this nature, we ought to regard as pretty concordant. The following are the results :-

\begin{tabular}{|c|c|c|c|c|}
\hline ptember & & & & \\
\hline & & & & \\
\hline October & 3. & & & $a=329 \cdot 72$ \\
\hline "י & 14. & & & $a=306.96$ \\
\hline & 21. & & . & $a=298.96$ \\
\hline December & 17. & & & $a=346 \cdot 70$ \\
\hline & 22. & & & $a=$ \\
\hline & & & & $a=32$ \\
\hline
\end{tabular}

The calculations made for four other days gave for mean value $a=318 \cdot 7$. Thus the mean of eight days was $a=323 \cdot 4$ divisions. In order to give an adequate idea of the exactness, I need only remark that, $a$ being represented in divisions of the galvanometer when sixteen Siemens units were introduced into the circuit, one division would correspond to $\frac{1}{10}$ of a degree; so that the greatest difference between the values of $a$ and the mean value is not more than 3 degrees.

I wished to find out what values $b$ ought to have in order that the formula should give for $a$ the value which we have just determined. I found that if we subtract 0.08 from each value of $b$ calculated, we obtain a number, $b_{1}=b-0.08$, which gives satisfactory values for $a$. Thus, if with the numbers deduced from the curves (Table VIII.), we reckon the value of $a$ by the formula $y=a b_{1}^{\mathbf{e}}$, giving to $b_{1}$ the values found for $b$ (Table IX.) minus 0.08 , we have values which are not far from the mean, $a=323 \cdot 4$ (see the following Table).

\begin{tabular}{|c|c|c|c|c|}
\hline \multicolumn{5}{|c|}{ 28th September. } \\
\hline E. & $y$. & $b$. & $b_{1}$. & $a=\frac{y}{b_{1}}$. \\
\hline $\begin{array}{l}1 \cdot 4 \\
2 \cdot 0 \\
2 \cdot 6 \\
3 \cdot 2\end{array}$ & $\begin{array}{l}213.0 \\
191 \cdot 2 \\
172 \cdot 3 \\
158 \cdot 0\end{array}$ & $\begin{array}{l}0.835 \\
0.840 \\
0.865 \\
0.900\end{array}$ & $\begin{array}{l}0.755 \\
0.76 \\
0.785 \\
0.82\end{array}$ & $\begin{array}{l}315 \cdot 68 \\
331 \cdot 03 \\
323 \cdot 23 \\
298 \cdot 16\end{array}$ \\
\hline \multicolumn{5}{|c|}{ 29th September. } \\
\hline $\begin{array}{l}1 \cdot 4 \\
2 \cdot 0 \\
2 \cdot 6 \\
3 \cdot 2 \\
4 \cdot 4\end{array}$ & $\begin{array}{l}2106 \cdot 8 \\
184 \cdot 8 \\
166 \cdot 1 \\
\mathbf{3 5 3 \cdot 0} \\
\mathbf{J 3 2 . 7}\end{array}$ & $\begin{array}{l}0.822 \\
0.837 \\
0.872 \\
0.905 \\
0.909\end{array}$ & $\begin{array}{l}0.742 \\
0.757 \\
0.792 \\
0.825 \\
0.829\end{array}$ & $\begin{array}{l}314 \cdot 04 \\
322 \cdot 49 \\
304 \cdot 57 \\
283 \cdot 16 \\
308 \cdot 59\end{array}$ \\
\hline \multicolumn{5}{|c|}{ 21st October. } \\
\hline $\begin{array}{l}1 \cdot 8 \\
2 \cdot 4 \\
3 \cdot 0 \\
3 \cdot 6 \\
4 \cdot 2 \\
4 \cdot 8\end{array}$ & $\begin{array}{l}200.9 \\
179 \cdot 8 \\
166 \cdot 6 \\
156 \cdot 1 \\
146.1 \\
137.2\end{array}$ & $\begin{array}{l}0.831 \\
0.881 \\
0.897 \\
0.897 \\
0.896 \\
0.900\end{array}$ & $\begin{array}{l}0.751 \\
0.801 \\
0.867 \\
0.816 \\
0.820 \\
0.814\end{array}$ & $\begin{array}{l}328 \cdot 46 \\
306 \cdot 25 \\
305 \cdot 49 \\
323 \cdot 15 \\
343 \cdot 21 \\
355 \cdot 67\end{array}$ \\
\hline
\end{tabular}


Another proof of the rule which has just been indicated can be given. If from different curves we deduce the values of $y$ which correspond to one and the same value of $\epsilon$, we have, obviously, different numbers. As, for example, we have for $\epsilon=2 \cdot 7$ :-

\begin{tabular}{|c|c|c|c|c|c|}
\hline September & 28. & & & & $174 \cdot 0$ \\
\hline 1 & 29 . & & & & $163 \cdot 3$ \\
\hline & 30. & & & & $164 \cdot 0$ \\
\hline October & 2. & & & , & $160^{\circ} 0$ \\
\hline 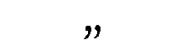 & 18. & & & - & $175^{\circ} 0$ \\
\hline " & 19. & • & & • & $169 \cdot 0$ \\
\hline$"$ & 21. & . & & & $172 \cdot 2$ \\
\hline & 10. & . & & & $172 \cdot 4$ \\
\hline November & 1. & . & & & $164 \cdot 0$ \\
\hline December & 10. & . & & & $168 \cdot 0$ \\
\hline 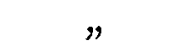 & 17. & • & & & $180 \cdot 0$ \\
\hline & 22. & & & & $162 \cdot 2$ \\
\hline
\end{tabular}

The arithmetic mean of these values is $y=168.7$; and if we determine the mean value of $b$ corresponding to $\epsilon=2 \cdot 7$, we obtain the number

$$
b=0 \cdot 86 .
$$

By making $b_{1}=0.86-0.08=0.78$, and by substituting the values of $y$, of $b$, and of $\epsilon$ in the formula $y=a b_{1}^{e}$, we obtain

$$
a=330 \text {, }
$$

a value which is very near the mean 323 . If, instead of $b_{1}=0.78$, we had taken the values 0.75 and 0.80 , we should have had respectively the values 308 and 367 for $a$, which shows that a very slight difference in the value of the coefficient of absorption $b$ is sufficient to give very different values for $a$; but that proves also that the method followed in determining the mean value of $a$ is very appropriate, since the extreme values amongst those of which the mean has been taken are nearer to the latter than those which are obtained by varying the coefficient of absorption 2 or 3 hundredths.

We can therefore confidently assume that the value $a=323$ represents the solar constant expressed in scale-divisions of the galvanometer employed when there was a resistance of sixteen Siemens units in the circuit, in addition to that offered by the pile No. 1, the rheophores, and the wire of the galvanometer.

It is now only necessary to determine what the value of $a$ signifies, in order to be able to compare the thermal effect produced by the radiation of the sun with that produced by the radiation from the artificial sources, and so determine in the end the effective temperature of the sun. 
X. Determination of the effective Temperature of the Sun.

We have seen that the thermal effect which the solar radiation, falling perpendicularly on the blackened face of pile No. 1, would produce if there were no atmosphere, or if the pile were situated at the higher limit of the atmosphere, is expressed by

$$
a=323 \text { divisions. }
$$

The solar observations were made with sixteen Siemens resistance units introduced into the circuit, whilst those on the radiation from artificial sources were made with no other resistance in the circuit than that offered by the pile itself, the rheophores, and the wire of the galvanometer. In short, in order to compare the solar observations with the others and to apply to them the formula, it is necessary to convert the value of $a=323$ into the value $y$, which would have given the same solar radiation if the sixteen Siemens units had been omitted. For this purpose it is necessary to find the resistance offered by the pile, the rheophores, and the wire of the galvanometer. The mean value from a dozen experiments was 3.408 Siemens units. The values furthest from the mean were 3.374 and 3.496 . Nine experiments made another day gave a mean value of $3 \cdot 411$. I therefore took $R=3 \cdot 41$ Siemens units to express the total resistance. Separately, the resistances were:-

The wire of the galvanometer . $r=1.522$

The rheophores . . . . . . $r_{1}=0.552$

The pile No. 1 . . . . . . . $r_{2}=1.336$

The value of $y$ can now be easily calculated:

Since $a=323$,

$$
y=\frac{\mathrm{R}+16}{\mathrm{R}} a=\frac{19 \cdot 41}{3 \cdot 41} a=5 \cdot 6921 a \text {. }
$$

$$
y=1838 \cdot 5 \text { divisions. }
$$

The effective temperature of the sun may be defined as that temperature which an incandescent body of the same size placed at the same distance ought to have in order to produce the same thermal effect $y$ if it had the maximum emissive power, i. e. $\mathrm{E}=1$. In this case we could apply the formula

$$
y=m \mathrm{~T}^{2}(\mathrm{~T}-\theta)-n(\mathrm{~T}-\theta) \text {; }
$$

and if we consider the surrounding temperature during the observations to have been about $24^{\circ}$, giving $\theta=297$, we obtain

$$
\mathrm{T}=10238^{\circ} \cdot 4 \text {; }
$$

so that the effectire temperature of the sun, represented in 
degrees Centigrade, is

$$
t=9965^{\circ} \cdot 4 \text {, }
$$

if we only take into consideration the absorption produced by the terrrestrial atmosphere. If we neglected this absorption we should have a lower temperature. In short, in the observations made, the maximum was obtained on September 28th at midday : this is represented by 210 scale-divisions, which gives for $y$ the value

$$
y=5 \cdot 6921 \times 210=1195 \cdot 3 .
$$

If we introduce this value into the formula, we obtain

giving

$$
\mathrm{T}=8883 \cdot 8 \text {, }
$$

$$
t=8610 \cdot 8 \text {. }
$$

This result will be greatly modified if we take into account the absorption exercised by the solar atmosphere. According to Secchi, the solar atmosphere exercises a very powerful absorption on the rays which proceed from the photosphere: on account of this absorption only 12 of the solar radiation pass beyond the atmosphere of the sun, whilst $\frac{88}{100}$ are absorbed by it. If we regard this value given by Secchi as correct, we can calculate the thermal effect which the sun would produce if it were without atmosphere. This effect would be

$$
y=1838 \cdot 5 \times \frac{100}{12}=15320 \cdot 8 .
$$

The formula gives

$$
\mathrm{T}=20653 \cdot 7 \text {, }
$$

and consequently

$$
t=20380 \cdot 7 \text {. }
$$

There are still two causes which can modify these results; but certainly their effect is slight, since their influences are contrary and so compensate one another. One of these causes is the value of the specific emissive power of the sun, which may possibly be less than unity; and in that case the true temperature of the sun would be higher. The other cause is the transparency of the different strata of the solar atmosphere: although this is small, it is nevertheless certain that we receive the rays from several superposed strata; and although their temperature is certainly lower than that of the photosphere situated underneath, nevertheless to the radiation of the latter a portion of the radiation of these strata joins itself; and consequently in that case a lower temperature of the sun is sufficient to produce the heating measured by our instruments. 
I think, then, that I may fairly conclude that the true temperature of the sun is not very different from its effective temperature, and that it is not much less than ten thousand degrees if we only consider the absorption of the terrestrial atmosphere, nor much more than twenty thousand degrees if we also take into consideration the absorption by the solar atmosphere, estimating the latter at $\frac{88}{100}$ of the total radiation of the sun.

\section{On the Influence of the Solar Rays on Vegetation. By Robert Hunt, F.R.S.}

To the Editors of the Philosophical Magazine and Joumal. Gentlemen,

A $S$ the first publication of the results obtained by me, in A my investigations into the influence of the Solar Rays on Vegetation, was in the Philosophical Magazine for April 1840 , I hope you will allow me to remove a wrong impression made by a paragraph in the Address of the President of the British Association at Sheffield, and explain the reason of my delay in doing so.

Dr. Allman stated that Messrs. Draper and Pfeffer had recently observed "that the solar spectrum is not equally effective in all its parts" in its influence on the growth of plants, thus leaving it to be inferred that this observation was new with them.

After the meeting (at which I was not present) I at once (August 25th) referred Dr. Allman to my papers on this subject. These are to be found in the Philosophical Magazine, as stated above, and in the Reports of the British Association for $1842,1843,1844$, and 1846 ; all of which were summarized in $\mathrm{my}$ ' Researches on Light,' the first edition of which work was published in 1844 . I was favoured with a reply from Dr. Allman on the 29th of August. After regretting that he had overlooked my investigations, he adds, "I need not say that I shall do all I can to correct the omission, and shall certainly take care that before the admission of the Address into the Transactions of the Association due justice shall be done to you in it."

With this I rested content, until I received a letter from Dr. Allman, dated November 9th, in which he writes, "I am truly sorry to say that the Transactions of the British Association have stolen a march on me, and come out without 